\title{
Sports participation with Chiari I malformation
}

\author{
*Jennifer Strahle, MD, ${ }^{1}$ Ndi Geh, BS, MSCR, ${ }^{1}$ Béla J. Selzer, NP, ${ }^{1}$ Regina Bower, MD, ${ }^{2}$ \\ Mai Himedan, BS, ${ }^{1}$ MaryKathryn Strahle, BS, ${ }^{1}$ Nicholas M. Wetjen, MD, ${ }^{2}$ Karin M. Muraszko, MD, ${ }^{1}$ \\ Hugh J. L. Garton, MD, MHSc, ${ }^{1}$ and Cormac O. Maher, MD'
}

\begin{abstract}
${ }^{1}$ Department of Neurosurgery, University of Michigan, Ann Arbor, Michigan; and ${ }^{2}$ Department of Neurosurgery, Mayo Clinic, Rochester, Minnesota
\end{abstract}

OBJECTIVE There is currently no consensus on the safety of sports participation for patients with Chiari I malformation (CM-I). The authors' goal was to define the risk of sports participation for children with the imaging finding of CM-I.

METHODS A prospective survey was administered to $503 \mathrm{CM}$-I patients at 2 sites over a 46-month period. Data were gathered on imaging characteristics, treatment, sports participation, and any sport-related injuries. Additionally, 81 patients completed at least 1 subsequent survey following their initial entry into the registry and were included in a prospective group, with a mean prospective follow-up period of 11 months.

RESULTS Of the $503 \mathrm{CM}$-I patients, 328 participated in sports for a cumulative duration of 4641 seasons; 205 of these patients participated in contact sports. There were no serious or catastrophic neurological injuries. One patient had temporary extremity paresthesias that resolved within hours, and this was not definitely considered to be related to the CM-I. In the prospective cohort, there were no permanent neurological injuries.

CONCLUSIONS No permanent or catastrophic neurological injuries were observed in CM-I patients participating in athletic activities. The authors believe that the risk of such injuries is low and that, in most cases, sports participation by children with $\mathrm{CM}-\mathrm{I}$ is safe.

http://thejns.org/doi/abs/10.3171/2015.8.PEDS15188

KEY WORDS Chiari malformation; concussion; incidence; injury; safety; sports

$\mathrm{C}$ HIARI I malformation (CM-I) is a common reason for neurosurgical referral. In our experience, one of the most pressing concerns of patients and their parents during these encounters has been to obtain a recommendation regarding sports participation that may be considered safe. There is currently no consensus on the safety of sports participation for those patients with CM-I. For the past 4 years, we systematically surveyed patients in our practice on their sports participation and sports-related injuries and now report on a large registry of patients with CM-I who have participated in sports. Our goal was to define the neurological risk of athletic participation for patients with CM-I.

\section{Methods}

This study was approved by the University of Michigan and Mayo Clinic Institutional review boards. A pro- spective survey on sports participation was administered to patients with a diagnosis of CM-I seen in the pediatric neurosurgery clinic at the University of Michigan from December 2010 to October 2014. An identical survey was administered to all patients with CM-I who were seen by a pediatric neurosurgeon at the Mayo Clinic from December 2010 to August 2013 (Fig. 1). Using this survey, we recorded demographic, imaging, and sports participation information for each individual. Demographic information included date of birth and date of CM-I diagnosis. Imaging information included tonsil position relative to the foramen magnum, tonsil morphology, and the presence/absence of a syrinx. For the purpose of this analysis, tonsils were considered rounded or pegged according to our previously described methods. ${ }^{41}$ For inclusion into this registry, patients must have been evaluated by the neurosurgery department at either center during the study period

ABBREVIATIONS $\mathrm{CM}-\mathrm{I}=$ Chiari I malformation.

SUBMITTED April 3, 2015. ACCEPTED August 10, 2015.

INCLUDE WHEN CITING Published online December 4, 2015; DOI: 10.3171/2015.8.PEDS15188.

* Dr. Strahle and Mr. Geh contributed equally to this work. 


\section{OUESTIONNAIRE}

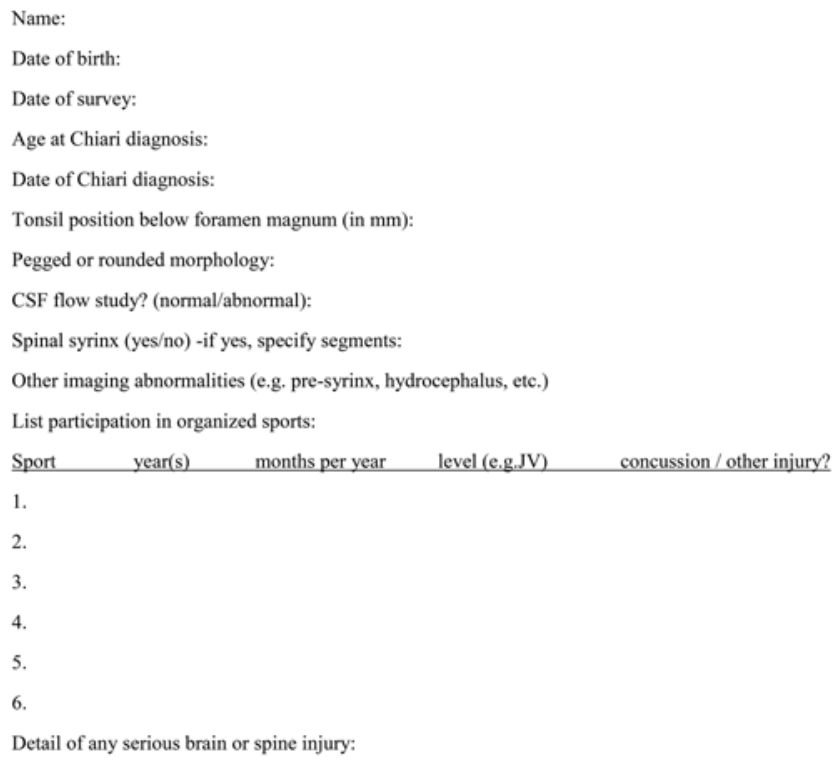

FIG. 1. Questionnaire administered to patients with CM-I.

and their lesions must have met minimal imaging criteria for CM-I with or without an associated syrinx according to our previously defined methods. ${ }^{42,43}$ For this analysis, those with CM-I must have had cerebellar tonsils at least $5 \mathrm{~mm}$ below the foramen magnum and those with syrinx must have had a spinal cord cavitation at least $3 \mathrm{~mm}$ in maximal axial diameter. In our practice, we no longer routinely order CSF flow studies on MRI. Nevertheless, patients still frequently present with these studies and their results were recorded in those cases. For the purpose of this analysis, CSF flow was considered abnormal at the foramen magnum if that was the documented opinion of the interpreting radiologist.

Sports information recorded included the type of sport, level of sport activity (junior levels, middle school, high school, or higher), dates and duration of participation, and details on any sports injury that occurred. Following the American Academy of Pediatrics classification of sports according to degree of contact, we considered baseball, basketball, dodgeball, football, hockey, lacrosse, martial arts, rugby, soccer, softball, ultimate Frisbee, water polo, and wrestling to be contact sports. ${ }^{37}$ All other sports were considered noncontact sports. Details of each sports injury were recorded. Sport participation was recorded according to number of months and number of seasons. A season was defined as a 3-month period for the purpose of this analysis. For patients who did not receive a survey in clinic, an identical survey was administered by phone. Some patients were evaluated on more than 1 clinical encounter. These patients completed a survey at the time of each encounter. All sports activities that occurred prior to the first encounter were considered retrospective and any activities that occurred between the first and any subsequent survey were considered prospective.

In general, our practice has been permissive with respect to sports participation for CM-I patients. Patients with a large cervical syrinx or symptoms clearly referable to the CM-I are generally treated surgically in our practice. These patients are advised to not participate in sports preoperatively but are allowed to resume sporting activities 3 months postoperatively if the syrinx has improved and the recovery is uneventful. Asymptomatic patients with no syrinx are not treated surgically in our practice and, in general, are not restricted from participation in any sports. For these patients, we have a detailed discussion with the patient and family regarding the potential risks and benefits of sports participation for each individual patient but do not proscribe any activity.

SAS software version 9.4 (SAS Institute) and Microsoft Excel (Microsoft Corp.) were used for data analysis. Injury rates were calculated using injury events as a numerator and seasons of sports participation as well as number of participants as denominators. Confidence intervals were calculated for rates determined by seasons of participation as well as number of participants. ${ }^{52}$ Injury incidence rates were calculated for all sports and contact sports.

\section{Results}

In this study, 466 patients with CM-I presented to the pediatric neurosurgery clinic at the University of Michigan between December 2010 and October 2014, and 103 patients with CM-I presented to the pediatric neurosurgery clinic at the Mayo Clinic between December 2010 and August 2013. Of the total 569 patients, 503 had survey data and were enrolled in our sports participation registry and 328 had participated in sports. Of the 328 sports participants, 175 were girls and 153 were boys. Two hundred five patients participated in contact sports. Many patients participated in multiple sports. In the entire cohort, a total of 13,922 months of sports participation or 4641 seasons of sports participation were recorded (Fig. 2; Table 1). The mean age at diagnosis was $8.7 \pm 6.5$ years for all patients and $10.7 \pm 6.2$ years for those who participated in sports. The mean age at time of survey administration was $11.9 \pm 6.6$ years. Sports participants were also older at the time of survey $(13.9 \pm 5.8$ years $)$ compared with those who did not play any sports $(8.1 \pm$ 6.5 years $)(p<0.0001)$.

There was no difference in mean tonsil position below the foramen magnum according to sports participation $(p=0.70)$ or history of concussion $(p=0.72)$. Those who participated in sports had a mean tonsil position $11.5 \pm$ $5.4 \mathrm{~mm}$ below the foramen magnum compared with 11.2 $\pm 7.1 \mathrm{~mm}$ for those who did not play any sports. Patients who had a concussion had a mean tonsil position of $11.7 \pm$ $5.7 \mathrm{~mm}$ and those who had not sustained any concussions had a mean tonsil position of $11.3 \pm 6.1 \mathrm{~mm}$. There was no difference in tonsil position according to sex in this select group of CM-I patients $(\mathrm{p}=0.56)$. Boys had a mean tonsil position of $11.2 \pm 5.3 \mathrm{~mm}$ and girls had a mean tonsil position of $11.5 \pm 6.7 \mathrm{~mm}$. Pegged tonsils were found in a majority of all patients in the registry $(323 / 439 ; 74 \%)$, as well as in a majority of sports participants $(198 / 328 ; 60 \%)$. CSF flow analysis on MRI was performed in 284 patients. Of these, there were 209 patients (74\%) with evidence of abnormal CSF flow at the foramen magnum. In the regis- 


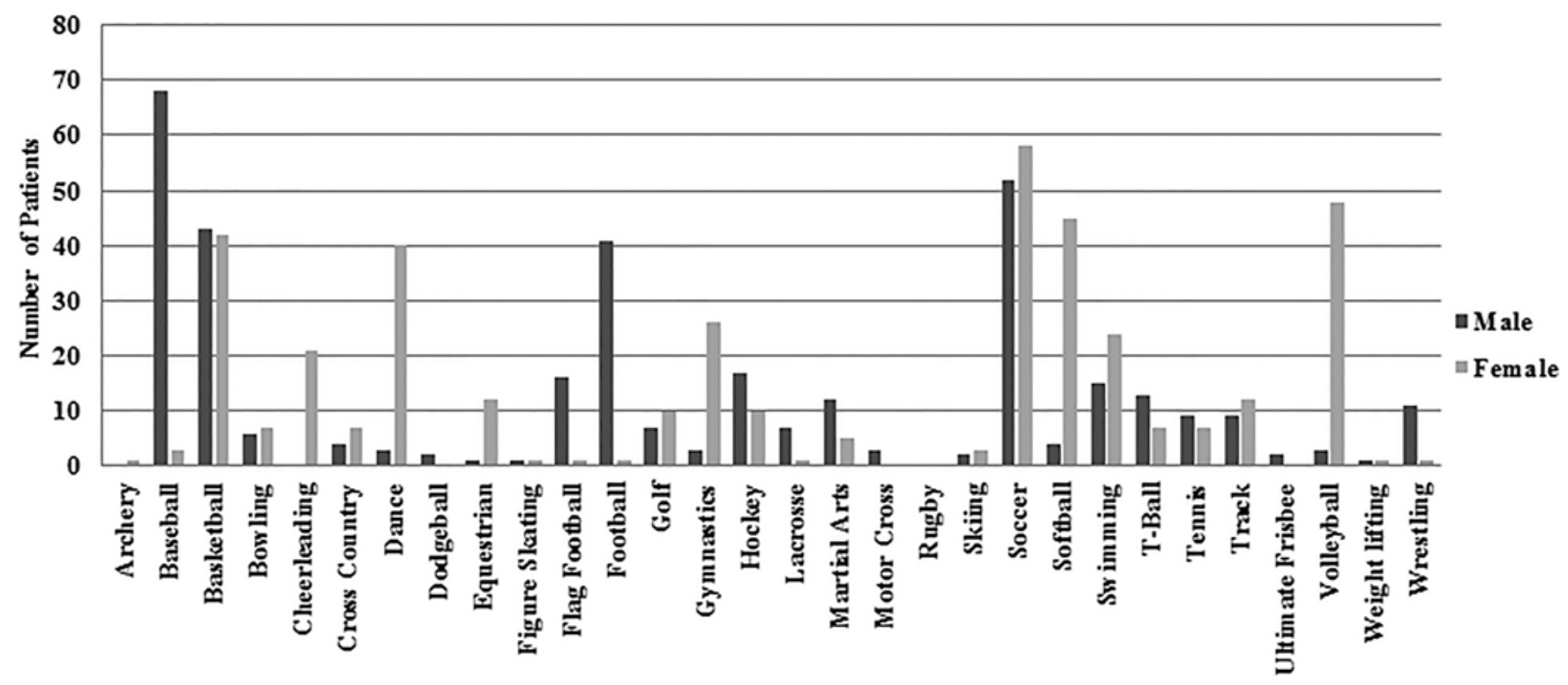

FIG. 2. Patient athletic participation by type of sport and sex $(n=328)$.

try, 124 of 503 patients (25\%) had a syrinx, and 93 of 328 $(28 \%)$ of the sports participants had a syrinx.

There were 33 sports-related concussions in 25 patients in the registry (8 patients had more than 1 concussion). Concussion occurred most frequently during soccer $(\mathrm{n}=$ $9)$, football $(\mathrm{n}=8)$, and hockey $(\mathrm{n}=8)$. Concussion was more likely to occur in contact sports. The concussion rate was $7 / 1000$ seasons for all patients who participated in sports and 12/1000 seasons for patients participating in contact sports. A comparison may be made with a similar registry at the University of Michigan containing cases of arachnoid cysts in 112 patients who participated in sports. In the cyst registry we found a concussion rate of $12 / 1000$ seasons for all sports and 17/1000 seasons for contact sports.

One patient had neurological symptoms other than concussion during sports participation. We did not consider this a sports-related injury caused by CM-I since the MRI appearance was not concerning to us at the time of evaluation. Nevertheless, we present case details here to allow others to form their own opinions on causation. This patient presented with transient numbness in the left arm and bilateral lower extremities, as well as generalized weakness after falling while playing soccer. She was taken to the emergency department within 30 minutes of her injury. The results of her neurological examination were normal at the time of emergency department evaluation. Her subjective symptom of numbness completely resolved in less than 6 hours without treatment. MRI showed the position of the tonsils to be $5 \mathrm{~mm}$ below the foramen magnum and the tonsils to have a rounded appearance (Fig. 3 ). The patient continues to participate in sports and remains at neurological baseline 2 years after the injury. We did not consider the borderline low tonsil position in this patient to be a likely cause of the symptoms and no treatment was recommended. This case was included in the retrospective data acquisition. Depending on if this patient is considered to have sustained a CM-related injury, our injury rate was either $0(95 \% \mathrm{CI} 0.00 \%-0.08 \%)$ or $1(95 \%$ CI $0.00 \%-0.12 \%$ ) per 4641 seasons of sports participation excluding concussions. There were 328 sports participants in the study, resulting in an injury rate of 0 of $328(95 \%$ CI $0.00 \%-1.12 \%)$ or 1 of $328(95 \%$ CI $0.01 \%-1.69 \%)$ per participant. There were 205 patients who participated in contact sports, resulting in an injury rate of 0 of 205 (95\% CI $0.00-1.78 \%$ ) or 1 of 205 (95\% CI $0.01-2.69 \%)$ per contact sport participant.

Eighty-one patients completed at least 1 survey after their initial data were recorded and were included in a prospective registry, with a mean prospective follow-up interval of $11.4 \pm 10.0$ months. No patients were instructed to avoid sports participation, and all but 3 of these patients continued to participate in sports. A single patient in this group sustained a concussion during the prospective follow-up period. Following her injury, this patient experienced a holocephalic headache with no significant tussive component as well as nausea that resolved over several days. No other neurological injuries were noted in the prospective group. Within the prospective group, 24 patients underwent $\mathrm{CM}$ decompression. Of these, 16 patients participated in at least 1 sports season postoperatively; 2 of these patients participated at a high school level.

\section{Discussion}

CM-I is a common reason for neurosurgical referral. An increasingly large number of patients with CM-I are being discovered incidentally., $4,11,25,32,41,43,44$ In our experience, care providers are frequently asked to provide recommendations to CM-I patients and their families regarding what level of sports participation should be considered safe. The American Academy of Pediatrics has periodically made recommendations for participation in sports..$^{26-28,37}$ No recommendations were made in these statements regarding patients with CM-I, although the most recent report by this 
TABLE 1. Cohort of 328 sports participants with CM-I dichotomized by sport, level of competition, and number of concussions

\begin{tabular}{|c|c|c|c|c|c|c|c|c|}
\hline \multirow[b]{2}{*}{ Sport } & \multirow[b]{2}{*}{ Male† } & \multirow[b]{2}{*}{ Female† } & \multicolumn{2}{|c|}{ Sports Participation* } & \multirow[b]{2}{*}{ Concussions } & \multicolumn{3}{|c|}{ Level of Participation } \\
\hline & & & $\begin{array}{l}\text { No. of } \\
\text { Months }\end{array}$ & $\begin{array}{l}\text { No. of } \\
\text { Seasons }\end{array}$ & & $\begin{array}{c}\text { Community/Recreation } \\
\text { League }\end{array}$ & $\begin{array}{l}\text { Middle } \\
\text { School }\end{array}$ & $\begin{array}{l}\text { High School } \\
\text { \& Above }\end{array}$ \\
\hline Archery & 0 & 1 & 24 & 8.0 & 0 & 1 & 0 & 0 \\
\hline Baseball & 68 & 3 & 1058.5 & 352.8 & 0 & 42 & 8 & 10 \\
\hline Basketball & 43 & 42 & 1190.5 & 396.8 & 3 & 85 & 24 & 29 \\
\hline Bowling & 6 & 7 & 322 & 107.3 & 0 & 4 & 8 & 1 \\
\hline Cheerleading & 0 & 21 & 595 & 198.3 & 0 & 5 & 3 & 11 \\
\hline Cross country & 4 & 7 & 117 & 39.0 & 0 & 0 & 4 & 4 \\
\hline Dance & 3 & 40 & 1841 & 613.7 & 0 & 23 & 8 & 7 \\
\hline Dodgeball & 2 & 0 & 18 & 6.0 & 1 & 1 & 0 & 0 \\
\hline Equestrian & 1 & 12 & 587 & 195.7 & 0 & 6 & 1 & 2 \\
\hline Figure skating & 1 & 1 & 154 & 51.3 & 1 & 1 & 1 & 0 \\
\hline Flag football & 16 & 1 & 77.5 & 25.8 & 0 & 14 & 1 & 0 \\
\hline Football & 41 & 1 & 645 & 215.0 & 8 & 10 & 6 & 19 \\
\hline Golf & 7 & 10 & 240 & 80.0 & 0 & 2 & 2 & 11 \\
\hline Gymnastics & 3 & 26 & 495.5 & 165.2 & 0 & 23 & 1 & 2 \\
\hline Hockey & 17 & 10 & 894.5 & 298.2 & 8 & 9 & 2 & 11 \\
\hline Lacrosse & 7 & 1 & 56 & 18.7 & 0 & 0 & 3 & 2 \\
\hline Martial arts & 12 & 5 & 476 & 158.7 & 0 & 7 & 1 & 2 \\
\hline Motocross & 3 & 0 & 90 & 30.0 & 0 & 2 & 0 & 0 \\
\hline Rugby & 0 & 0 & 0 & 0.0 & 0 & 0 & 0 & 0 \\
\hline Skiing & 2 & 3 & 62.5 & 20.8 & 1 & 59 & 9 & 27 \\
\hline Soccer & 52 & 58 & 2330.4 & 776.8 & 9 & 22 & 8 & 12 \\
\hline Softball & 4 & 45 & 673.5 & 224.5 & 0 & 4 & 1 & 0 \\
\hline Swimming & 15 & 24 & 565 & 188.3 & 0 & 21 & 6 & 6 \\
\hline Tee ball & 13 & 7 & 72 & 24.0 & 0 & 18 & 0 & 0 \\
\hline Tennis & 9 & 7 & 251 & 83.7 & 0 & 4 & 3 & 8 \\
\hline Track & 9 & 12 & 195 & 65.0 & 0 & 2 & 6 & 8 \\
\hline Ultimate Frisbee & 2 & 0 & 1 & 0.3 & 1 & 1 & 0 & 0 \\
\hline Volleyball & 3 & 48 & 641.5 & 213.8 & 0 & 9 & 18 & 22 \\
\hline Weight lifting & 1 & 1 & 42 & 14.0 & 0 & 0 & 0 & 0 \\
\hline Wrestling & 11 & 1 & 207 & 69.0 & 1 & 3 & 2 & 6 \\
\hline Totals & 355 & 394 & $13,922.4$ & 4640.7 & 33 & 378 & 126 & 200 \\
\hline
\end{tabular}

* Values represent cumulative participation.

† Some participants played multiple sports.

group suggests that any serious head or spine abnormality should be evaluated prior to sports participation. ${ }^{37}$ Individual opinions vary widely. Some have recommended that even asymptomatic patients with CM-I should avoid all contact sports, especially if the patient has presented with concussion. ${ }^{3,9,10,30}$ Others have suggested that patients should be disqualified from contact sports if there is evidence of obliteration of the subarachnoid space, a syrinx, or any evidence of indentation of the anterior medulla. ${ }^{17,35}$ Finally, some permit athletic participation if the CM-I is asymptomatic and the parents and athletic personnel are well-informed of the potential risks..$^{19,29}$

On two occasions, pediatric neurosurgeons have been surveyed on their approach to activity restriction for asymptomatic CM-I patients. ${ }^{16,40}$ Like the cited expert opinions, pediatric neurosurgeons in general do not appear to have a uniform approach to this scenario. In 1998, Haroun et al. ${ }^{16}$ surveyed members of the pediatric section of the American Association of Neurological Surgeons. In that survey, $36 \%$ of respondents recommended restricting the activity of asymptomatic patients with CM-I on imaging, and $42 \%$ recommended activity restriction if a syrinx was also present. Schijman and Steinbok ${ }^{40}$ performed a similar survey of the membership of the International Society for Pediatric Neurosurgery in 2004. They found that $45.9 \%$ of respondents would not restrict the activity of an asymptomatic girl with CM-I and a thin (3-mm) cervical syrinx and that $18.9 \%$ of this group would recommend avoiding contact sports.

There are very few reported cases of athletic injury 


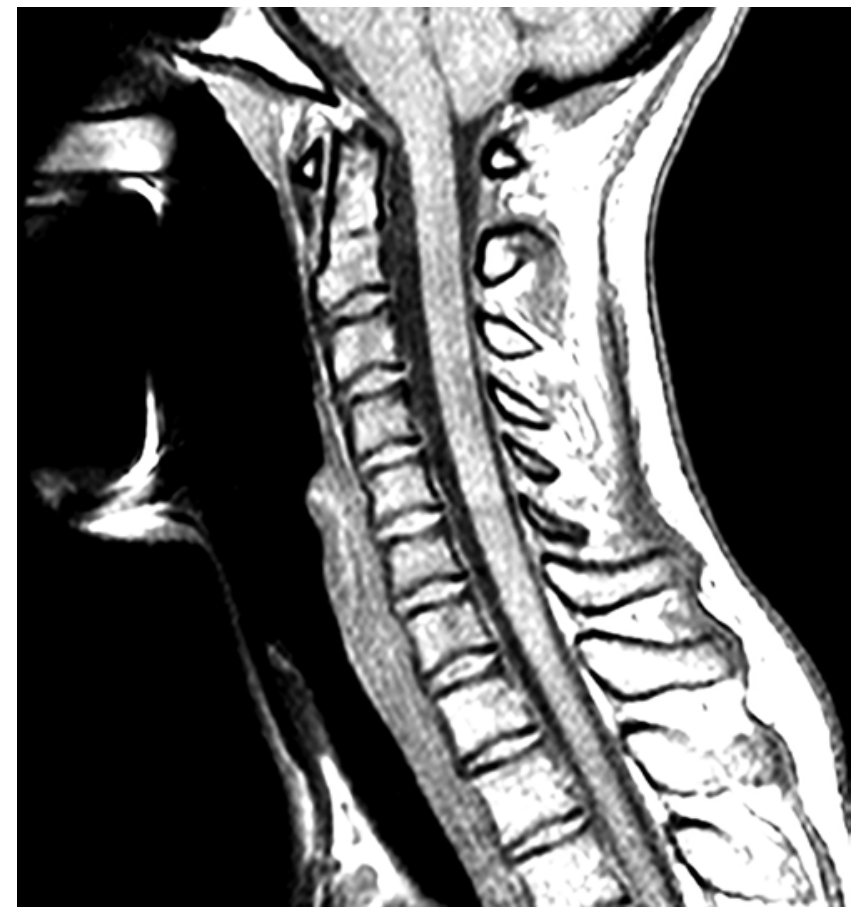

FIG. 3. Sagittal MR image of female patient who experienced transient neurological symptoms while playing soccer. The cerebellar tonsils measured $5 \mathrm{~mm}$ below the foramen magnum line; the tonsils were not peg shaped. The patient was not treated and her symptoms resolved within hours.

causing symptoms in CM-I patients, a fact that is surprising given the prevalence of CM-I. Callaway et al. ${ }^{7}$ reported on an 8-year-old child with CM-I who experienced transient lower-extremity paresthesias following an athletic injury. Frogameni et al. ${ }^{13}$ reported on a 20 -year-old with CM-I and syrinx who experienced weakness and paresthesias immediately following an injury sustained during weight-lifting. As part of a small case series of acute presentation of CM-I, Yarbrough et al. ${ }^{51}$ reported on a patient with CM-I and a syrinx who presented with arm paresthesia after a football injury. Like our own case, the causal relationship between the symptoms and a combination of the CM-I and athletic injury cannot be established with certainty in these cases.

Some retrospective case series have found that patients with CM-I will occasionally present with CM-I symptoms following a traumatic event. ${ }^{46,48}$ In the largest reported series of surgically treated CM-I in children, Tubbs et al. ${ }^{46}$ reported that 4 of their 500 patients $(0.8 \%)$ presented with symptoms of CM-I following trauma. Wan et al. ${ }^{48}$ reported on 3 patients with new symptoms attributed to a CM-I following trauma. None of these patients were reportedly injured while participating in sports. There are several other case reports of patients with CM-I in which patients presented following severe ${ }^{10,21,33,47}$ or more minor ${ }^{1,2,5,6,12,18,31,38,45,50}$ trauma. None of the traumatic events described in these case reports involved athletic injury. We believe it is important to examine these case reports in the context of what is known about CM-I. Given the prevalence of CM-I as an incidental finding, ${ }^{41,43,44}$ it is not surprising that some patients with posttraumatic neurological symptoms will have a CM-I. In some of these examples, it is not clear that the CM-I was the source of the new posttraumatic neurological findings. Even given these limitations, however, it does seem likely that posttraumatic presentation of symptomatic CM-I can occur in some instances.

Concussion is a common athletic injury, so it is not surprising that we have found that some individuals with CM-I will have a concussion during sports participation. The concussion incidence reported here is similar to that anticipated in the general pediatric population. ${ }^{3,20,22,39}$ Concussion rates vary according to type of sport. Recent studies have found concussion rates of $6.7 \%-25 \%$ per season for all participants in high school football or hockey, ${ }^{8,14,23,49} 2 \%$ per season for basketball, ${ }^{15}$ and $1 \%$ per season for baseball. ${ }^{34}$ As expected, we found a higher concussion incidence in contact sports compared with noncontact sports.

We reported on a single patient that had nonconcussive neurological symptoms during sports participation. We believe that it is difficult to ascribe causation to his cerebellar tonsil morphology in this case, but we acknowledge that this is a subjective judgment. For this reason, we have presented the clinical and imaging information for this patient so that others may form their own conclusions about the causation of these symptoms. Importantly, even if the symptoms were caused by the combination of sports participation and the CM-I, this patient suffered no lasting harm and required no treatment. On this basis, we believe that there is no foundation to the prohibition of athletic participation for most children with CM-I. This conclusion is supported by a recent mail survey of sports participation for CM-I patients. ${ }^{29}$ Meehan et al. ${ }^{29}$ recently surveyed 300 CM-I patients. They had 147 respondents who participated in 1627 athletic seasons, including 191 collision sport seasons, and found no serious injuries resulting in death, coma, or paralysis. Their results support the conclusions that we have drawn from our own registry results regarding the safety of sports participation for most children with CM-I.

Prior reports that examined the rate of sports injury have used several different metrics. Many groups report on injury rates according to injuries per 1000 athlete exposures using the National High School Sports-Related Injury Surveillance System's data collection tool, the High School Reporting Information Online (RIO). ${ }^{20,22,36,39}$ In these reports, an athlete exposure is 1 athlete participating in 1 practice or competition..$^{36}$ The nature of our registry data did not allow for examination of individual athlete exposures in this report without making assumptions about the number of exposures in each time period. Instead, we chose to record injury rates and concussion rates according to events per 1000 sports seasons (defined as 3 months for this study) or sports months. Reporting injury rates per season is an accepted method of reporting injury rates $8,14,15,23,34,49$ and we think it is a more appropriate incidence unit, given our available data.

There are several important limitations to this analysis. Most of the injury information in this registry was retrospective. Patients or their families were asked to re- 
member details of athletic participation as well as their injury history. It is possible that some injuries were not recorded because the patient or family had forgotten about the athletic participation or an injury event. We suspect that recall bias would be more likely to affect level of athletic participation than injury information, since we believe that families are more likely to remember significant injuries. Concussion events and other injury events were self-reported. Events were considered concussion if the patient or family reported an event that was considered consistent with this diagnosis. ${ }^{24}$ Despite these methodological limitations, the concussion experience described by patients in our study is similar to that of other reported series of concussion in sports. We report injury rates according to number of seasons played as well as the overall number of participants. In general, risk factors should be evaluated according to extent of exposure when exposure differs among participants, as is the case in this group. Therefore, we think that the rate presented as injuries per season, rather than per participant, is the most useful way of interpreting this information.

All patients were referred for neurosurgical evaluation, and this group may not be representative of all patients with a CM-I who are not referred for subspecialty care. We do not believe that this selected group of CM-I patients should have any decreased risk of sports injury compared with others with CM-I.

Calling an activity "safe" requires a judgment relative to some subjective standard for a level of acceptable safety. No contact sports can be called truly safe for any individual if the standard is one of absolute safety-i.e., an expectation that no injuries will ever occur. Such a strict standard is not employed for the general population and, in our opinion, should not be employed for patients with CM-I. If it is agreed that the absolute safety standard is not practical, we are then left to decide how safe is "safe enough." Continued prospective acquisition of athletic participation and injury data will lead to better definitions of risk in the future. Future study will be especially important to evaluate subsets of patients that are relatively less well represented in our own cohort, such as postoperative CM-I patients or CM-I patients participating at a high level in sports that are associated with substantial risk of contact injury for any participant.

\section{Conclusions}

We have reported on 503 patients with CM-I enrolled in a sports participation registry and found no permanent, significant neurological injuries in this group. We conclude that neurological injuries for CM-I patients participating in sports are rare. On the basis of these data, we believe that we are justified in continuing our current permissive practice with respect to sports participation. We hope that the registry data we have presented will reassure patients and care providers that sports participation is safe for patients with CM-I in most cases.

\section{Acknowledgments}

We would like to thank Holly Wagner for providing editorial assistance.

\section{References}

1. Ajis A, Dharmarajah R: Prolonged recovery of balance after a minor head injury as the only presenting feature of Chiari 1 malformation. Br J Neurosurg 18:398-400, 2004

2. Alegre S, García-Rubira JC, Patrignani G: Cardiac arrest in a 31-year-old man because of the Arnold-Chiari malformation. Int J Cardiol 46:286-288, 1994

3. Bailes JE, Cantu RC: Head injury in athletes. Neurosurgery 48:26-46, 2001

4. Benglis D Jr, Covington D, Bhatia R, Bhatia S, Elhammady MS, Ragheb J, et al: Outcomes in pediatric patients with Chiari malformation Type I followed up without surgery. J Neurosurg Pediatr 7:375-379, 2011

5. Bondurant CP, Oró JJ: Spinal cord injury without radiographic abnormality and Chiari malformation. J Neurosurg 79:833-838, 1993

6. Bunc G, Vorsic M: Presentation of a previously asymptomatic Chiari I malformation by a flexion injury to the neck. J Neurotrauma 18:645-648, 2001

7. Callaway GH, O'Brien SJ, Tehrany AM: Chiari I malformation and spinal cord injury: cause for concern in contact athletes? Med Sci Sports Exerc 28:1218-1220, 1996

8. Collins M, Lovell MR, Iverson GL, Ide T, Maroon J: Examining concussion rates and return to play in high school football players wearing newer helmet technology: a three-year prospective cohort study. Neurosurgery 58:275-286, 2006

9. Couldwell WT: Comment on "Conversion to symptomatic Chiari I malformation after minor head or neck trauma." Neurosurgery 63:753, 2008

10. Couldwell WT, Zhang W, Allen R, Arce D, Stillerman CB: Cerebellar contusion associated with type I Chiari malformation following supratentorial head trauma: case report. Neurol Res 20:93-96, 1998

11. Elster AD, Chen MY: Chiari I malformations: clinical and radiologic reappraisal. Radiology 183:347-353, 1992

12. Erlich V, Snow R, Heier L: Confirmation by magnetic resonance imaging of Bell's cruciate paralysis in a young child with Chiari type I malformation and minor head trauma. Neurosurgery 25:102-105, 1989

13. Frogameni AD, Widoff BE, Jackson DW: Syringomyelia causing acute hemiparesis in a college football player. Orthopedics 17:552-553, 1994

14. Gerberich SG, Priest JD, Boen JR, Straub CP, Maxwell RE: Concussion incidences and severity in secondary school varsity football players. Am J Public Health 73:1370-1375, 1983

15. Gomez E, DeLee JC, Farney WC: Incidence of injury in Texas girls' high school basketball. Am J Sports Med 24:684-687, 1996

16. Haroun RI, Guarnieri M, Meadow JJ, Kraut M, Carson BS: Current opinions for the treatment of syringomyelia and Chiari malformations: survey of the Pediatric Section of the American Association of Neurological Surgeons. Pediatr Neurosurg 33:311-317, 2000

17. Harrell BR, Barootes BG: The type I Chiari malformation in a previously asymptomatic college athlete: addressing the issue of return to athletic participation. Clin J Sport Med 20:215-217, 2010

18. James DS: Significance of chronic tonsillar herniation in sudden death. Forensic Sci Int 75:217-223, 1995

19. Kirschen MP, Illes J: Ethical implications of an incidentally discovered asymptomatic Chiari malformation in a competitive athlete. Continuum (Minneap Minn) 20 (6 Sports Neurology):1683-1687, 2014

20. Lincoln AE, Caswell SV, Almquist JL, Dunn RE, Norris JB, Hinton RY: Trends in concussion incidence in high school sports: a prospective 11-year study. Am J Sports Med 39:958-963, 2011

21. Mampalam TJ, Andrews BT, Gelb D, Ferriero D, Pitts LH: 
Presentation of type I Chiari malformation after head trauma. Neurosurgery 23:760-762, 1988

22. Marar M, McIlvain NM, Fields SK, Comstock RD: Epidemiology of concussions among United States high school athletes in 20 sports. Am J Sports Med 40:747-755, 2012

23. McCrea M, Hammeke T, Olsen G, Leo P, Guskiewicz K: Unreported concussion in high school football players: implications for prevention. Clin J Sport Med 14:13-17, 2004

24. McCrory P, Meeuwisse W, Johnston K, Dvorak J, Aubry M, Molloy M, et al: Consensus statement on Concussion in Sport 3rd International Conference on Concussion in Sport held in Zurich, November 2008. Clin J Sport Med 19:185-200, 2009

25. Meadows J, Kraut M, Guarnieri M, Haroun RI, Carson BS: Asymptomatic Chiari Type I malformations identified on magnetic resonance imaging. J Neurosurg 92:920-926, 2000

26. American Academy of Pediatrics Committee on Sports Medicine and Fitness: Medical conditions affecting sports participation. Pediatrics 94:757-760, 1994

27. American Academy of Pediatrics Committee on Sports Medicine and Fitness: Medical conditions affecting sports participation. Pediatrics 107:1205-1209, 2001

28. American Academy of Pediatrics Committee on Sports Medicine and Fitness: Recommendations for participation in competitive sports. Pediatrics 81:737-739, 1988

29. Meehan WP III, Jordaan M, Prabhu SP, Carew L, Mannix RC, Proctor MR: Risk of athletes with Chiari malformations suffering catastrophic injuries during sports participation is low. Clin J Sport Med 25:133-137, 2015

30. Miele VJ, Bailes JE, Martin NA: Participation in contact or collision sports in athletes with epilepsy, genetic risk factors, structural brain lesions, or history of craniotomy. Neurosurg Focus 21(4):E9, 2006

31. Murano T, Rella J: Incidental finding of Chiari I malformation with progression of symptoms after head trauma: case report. J Emerg Med 30:295-298, 2006

32. Novegno F, Caldarelli M, Massa A, Chieffo D, Massimi L, Pettorini B, et al: The natural history of the Chiari Type I anomaly. J Neurosurg Pediatr 2:179-187, 2008

33. Olivero WC, Dinh DH: Chiari I malformation with traumatic syringomyelia and spontaneous resolution: case report and literature review. Neurosurgery 30:758-760, 1992

34. Pasternack JS, Veenema KR, Callahan CM: Baseball injuries: a Little League survey. Pediatrics 98:445-448, 1996

35. Proctor MR, Scott RM: Spinal cord abnormalities in sports. Clin Sports Med 31:521-533, 2012

36. Rechel JA, Yard EE, Comstock RD: An epidemiologic comparison of high school sports injuries sustained in practice and competition. J Athl Train 43:197-204, 2008

37. Rice SG: Medical conditions affecting sports participation. Pediatrics 121:841-848, 2008

38. Riviello JJ Jr, Marks HG, Faerber EN, Steg NL: Delayed cervical central cord syndrome after trivial trauma. Pediatr Emerg Care 6:113-117, 1990

39. Rosenthal JA, Foraker RE, Collins CL, Comstock RD: National High School Athlete Concussion Rates From 20052006 to 2011-2012. Am J Sports Med 42:1710-1715, 2014

40. Schijman E, Steinbok P: International survey on the management of Chiari I malformation and syringomyelia. Childs Nerv Syst 20:341-348, 2004

41. Smith BW, Strahle J, Bapuraj JR, Muraszko KM, Garton HJ, Maher CO: Distribution of cerebellar tonsil position: implica- tions for understanding Chiari malformation. J Neurosurg 119:812-819, 2013

42. Strahle J, Muraszko KM, Garton HJL, Smith BW, Starr J, Kapurch JR II, et al: Syrinx location and size according to etiology: identification of Chiari-associated syrinx. J Neurosurg Pediatr 16:21-29, 2015

43. Strahle J, Muraszko KM, Kapurch J, Bapuraj JR, Garton HJ, Maher CO: Chiari malformation Type I and syrinx in children undergoing magnetic resonance imaging. J Neurosurg Pediatr 8:205-213, 2011

44. Strahle J, Muraszko KM, Kapurch J, Bapuraj JR, Garton HJ, Maher CO: Natural history of Chiari malformation Type I following decision for conservative treatment. J Neurosurg Pediatr 8:214-221, 2011

45. Tomaszek DE, Tyson GW, Bouldin T, Hansen AR: Sudden death in a child with an occult hindbrain malformation. Ann Emerg Med 13:136-138, 1984

46. Tubbs RS, Beckman J, Naftel RP, Chern JJ, Wellons JC III, Rozzelle CJ, et al: Institutional experience with 500 cases of surgically treated pediatric Chiari malformation Type I. J Neurosurg Pediatr 7:248-256, 2011

47. Vlcek BW, Ito B: Acute paraparesis secondary to ArnoldChiari type I malformation and neck hyperflexion. Ann Neurol 21:100-101, 1987

48. Wan MJ, Nomura H, Tator $\mathrm{CH}$ : Conversion to symptomatic Chiari I malformation after minor head or neck trauma. Neurosurgery 63:748-753, 2008

49. Williamson IJ, Goodman D: Converging evidence for the under-reporting of concussions in youth ice hockey. Br J Sports Med 40:128-132, 2006

50. Wolf DA, Veasey SP III, Wilson SK, Adame J, Korndorffer WE: Death following minor head trauma in two adult individuals with the Chiari I deformity. J Forensic Sci 43:12411243, 1998

51. Yarbrough CK, Powers AK, Park TS, Leonard JR, Limbrick DD, Smyth MD: Patients with Chiari malformation Type I presenting with acute neurological deficits: case series. J Neurosurg Pediatr 7:244-247, 2011

52. Zar JH: Biostatistical Analysis. Upper Saddle River, NJ: Prentice Hall, 1996, pp 524-525

\section{Disclosures}

The authors have no conflicts of interest to report pertaining to the materials or methods used in this study or the findings specified in this paper.

\section{Author Contributions}

Conception and design: Maher. Acquisition of data: all authors. Analysis and interpretation of data: Maher, J Strahle, Geh, Selzer, Bower, Himedan, M Strahle, Wetjen. Drafting the article: Maher, J Strahle, Geh, Garton, Selzer. Critically revising the article: Maher, Bower, Strahle, Garton, Muraszko, Wetjen. Reviewed submitted version of manuscript: all authors. Approved the final version of the manuscript on behalf of all authors: Maher. Statistical analysis: Geh, Strahle. Administrative/technical/material support: Study supervision: Maher.

\section{Correspondence}

Cormac O. Maher, Department of Neurosurgery, University of Michigan, 1500 E. Medical Center Dr., Rm. 3552 Taubman Center, Ann Arbor, MI 48109-5338. email: cmaher@med.umich.edu. 